\title{
Quanto vale uma valência?
}

How valuable a valence is?

Nos estudos brasileiros sobre meios de comunicação e política, a "valência” é uma espécie de coringa, adaptada aos objetivos de cada um ${ }^{1}$. Pode ser evocada pela Folha de S. Paulo para afirmar sua própria imparcialidade ou alimentar as denúncias do defensores do governo federal contra a "imprensa golpista”. Graças a ela, conjunturas complexas são facilmente transformadas em variáveis numéricas, de acordo com uma escala bidimensional. Graças a ela, processos contraditórios e multifacetados podem assumir a forma de gráficos de linha, barras ou pizza, ganhando uma simplicidade visual sedutora. Graças a ela, dissipam-se as brumas de um esforço compreensivo sempre incompleto e frustrante e podemos estabelecer nossos enunciados com a precisão de duas casas depois da vírgula. O jornal A é 12,47\% mais imparcial que o jornal B. O antipetismo cresceu $38,77 \%$ de um ano para outro. A imagem pública de fulano é 29,04\% mais positiva que a de sicrano.

Usei "imparcial", no primeiro dos meus exemplos hipotéticos, e não foi por acaso. Neste artigo, busco demonstrar que o recurso à valência carrega três problemas principais, estreitamente ligados entre si e todos insolúveis. $\mathrm{O}$ primeiro, de uma ordem metodológica mais chã, é que ela confunde sistema-

\footnotetext{
Professor do Instituto de Ciência Política da Universidade de Brasília, onde coordena o Grupo de Pesquisa sobre Democracia e Desigualdades - Demodê. E-mail: Iuisfelipemiguel@gmail.com.

Versão inicial deste artigo foi discutida no VI Congresso da Associação Brasileira de Pesquisadores em Comunicação em Política (Compolítica), que ocorreu no Rio de Janeiro, de 22 a 24 de abril de 2015. Agradeço aos comentários, críticas e sugestões de Danila Cal, Flávia Biroli, Heloísa Dias Bezerra e Wilson Gomes, participantes do Congresso.
} 
ticamente diferentes planos de apreensão do jornalismo, colocando na mesma panela emissor, receptor, pesquisador e objeto do discurso. Em particular, ela introduz de contrabando uma presunção de compreensão da recepção das mensagens jornalísticas, poupando-se o trabalho de fazer pesquisa de recepção. O segundo é que ela necessariamente mutila a complexidade do processo comunicativo, a fim de adequá-lo a sua escala de "bom" e "mau"; no caminho mutilando também a complexidade da interface entre mídia e competição política. O que se perde com isso não é acessório, é o principal. Por fim, a valência reproduz, mesmo que muitas vezes de forma oculta, o ideal normativo da imparcialidade jornalística. O que a valência mede é o desvio em relação a essa imparcialidade. No entanto, a imparcialidade é uma ferramenta muito insuficiente, ou mesmo contraproducente, para a construção de uma crítica normativa, orientada pelo valor da democracia, da comunicação de massa.

Na primeira seção do artigo, discuto esta relação entre valência e imparcialidade, bem como os limites do apelo à imparcialidade como ideal normativo. $\mathrm{Na}$ segunda seção, discuto os outros dois problemas gerais que identifico na valência como ferramenta metodológica. Na conclusão, por fim, indico que não há substituto para a valência e que o jeito é abandonar o fetiche da matematização e trabalhar com um instrumental mais complexo para a compreensão do discurso do jornalismo e sua relação com os conflitos políticos.

\section{Valência e imparcialidade}

A valência se estabelece sempre em relação a um determinado agente (individual ou coletivo). Trata-se de saber se, em relação àquele agente, o viés do noticiário é mais elogioso ou mais crítico. Num estudo sobre uma competição eleitoral, pela equipe que mais contribuiu para consolidar os estudos de valência no Brasil (a equipe do laboratório Doxa, do antigo Iuperj), explica-se que o método é "verificar se a informação ou opinião veiculada, em si, é positiva ou negativa para o candidato, independente do propósito de prejudicar um ou outro" (Aldé, Mendes e Figueiredo, 2007, p. 158)². De maneira similar, o "Manchetômetro", produzido por outra equipe da mesma instituição e inspirado no próprio Doxa ${ }^{3}$, afirma que a análise é feita

Deixo para a próxima seção a discussão do qualificativo "em si", que é acrescentado como uma maneira de solucionar um problema (fazendo com que a análise seja independente do propósito do emissor), mas introduz muitos outros.

O"Manchetômetro"surgiu em 2014, com o propósito de dar verniz acadêmico às denúncias de viés da mídia contra a candidata presidencial à reeleição, Dilma Rousseff. Embora não cite o Doxa ou Marcus 
levando em conta a seguinte pergunta: essa manchete ou chamada, e o texto que a acompanha, é positiva, negativa, neutra ou ambivalente para a imagem do candidato, partido, pessoa ou governo a qual faz referência. Assim, não se trata de estabelecer se o que está sendo noticiado é verdadeiro ou falso, mas sim avaliar o significado daquela informação para a imagem do objeto do texto (Manchetômetro, 2014).

A análise da valência gera, então, uma mensuração, que tanto pode ser apresentada na forma de frequências simples (porcentagens de matérias positivas, negativas ou neutras) quanto de saldos de valências (proporção da positivas menos proporção das negativas) ou outros índices mais elaborados. Desvios acentuados na direção de valências positivas ou negativas indicariam parti pris favorável ou desfavorável àquele agente, por parte do veículo emissor dos discursos. Mais importante, porém, seria a comparação no tratamento dados aos agentes em disputa. Um tratamento equânime viés negativo para todos os candidatos a uma eleição, por exemplo - seria indicativo da imparcialidade.

Foi assim que a Folha de S. Paulo usou, mais de uma vez, as pesquisas do Doxa para afirmar que era mais imparcial que seus concorrentes (Beraba, 2004, 2006; Folha, 2010), depois produzindo seus próprios levantamentos, com a mesma intenção (Martins, 2014). Do outro lado, a denúncia relativa ao viés antipetista da mídia também utiliza os números da valência para embasar sua posição, algo que, nas últimas eleições, saiu dos trabalhos acadêmicos e tornou-se parte da campanha com a criação do site "Manchetômetro".

Como autoelogio ou como denúncia, o recurso à valência remete sempre a um valor subjacente: a imparcialidade jornalística. Segundo expressou com clareza outro adepto do método, o problema subjacente a tais pesquisas é que "a mídia pode usar critérios de noticiabilidade que terminam por beneficiar determinados candidatos em detrimento dos outros, seja por aspectos quantitativos (visibilidade) ou qualitativos (valência)" (Borba, 2005, p. 13). Assim, o critério implícito é que o jornalismo não deve dar mais destaque a um candidato (partido, político, líder etc.) em relação a outros, nem ter um viés diferenciado na cobertura sobre ele.

A aplicação desta lógica leva a resultados que são, no mínimo, intrigantes. Uma análise da cobertura da mídia impressa nas eleições presidenciais 
brasileiras de 2002 a 2010 chegou à conclusão de que, no quesito visibilidade, os jornais são bastante imparciais, pois noticiam com destaque tanto o PT quanto seus adversários:

Os dados analisados neste item não corroboram a hipótese do comportamento de classe da imprensa. Eles apontam para outra direção. Ao cobrirem as eleições presidenciais os jornais brasileiros adotaram como critério de visibilidade a posição ocupada pelos candidatos na disputa em termos de intenção de votos e a sua importância política. Ou seja, ao menos em termos de visibilidade, o critério de noticiabilidade dos jornais está mais próximo de uma mídia comercial do que de um posicionamento motivado por razões ideológicas dos proprietários dos veículos (Mundim, 2014, p. 16).

A associação mecânica entre visibilidade e não-viés merece ser questionada. É bem verdade que jornais do interior, às vezes, suprimem de suas páginas os adversários do prefeito. Mas será que - por exemplo - a revista Veja poderia ignorar o presidente da República, candidato à reeleição, em 2006 ou em 2014? E, por não ignorar, demonstrou neste quesito a sua isenção? O exemplo é trivial porque o problema é trivial. Trata-se da ideia de que nós podemos aplicar uma métrica que decifra o significado de um processo, sem que tenhamos que entender o processo em questão.

Seja como for, nesse tipo de análise fica implícito que a cobertura "correta" deve dar espaço proporcional à posição de cada candidato nas pesquisas de intenção de voto - é exatamente o teste que é feito no texto citado ${ }^{4}$. Mas será que é assim mesmo? Em primeiro lugar, as pesquisas não esgotam o conhecimento sobre a conjuntura política. A imprensa dedicou uma parcela signicativa de sua cobertura à pré-candidata Dilma Rousseff, antes das eleições de 2010, mesmo quando ela patinava abaixo dos dois dígitos nas sondagens pré-eleitorais, ciente de que o apoio do PT e do governo Lula a tornavam uma candidata competitiva. É por isso que o trecho do estudo citado apõe "importância política" a "intenção de votos", em prejuízo da objetividade e da mensurabilidade pretendidas por seu critério.

Mas, do ponto de vista do funcionamento da democracia, não seria talvez mais adequado buscar dar espaço igual a todos os candidatos competitivos? Com isso, o eleitor teria condições de decidir melhor entre Lula e Alckmin, entre

Todas as questões de que trato aqui, relativas à visibilidade na mídia, valem, mutatis mutandis, para o teor da cobertura, isto é, para a valência. 
Dilma e Serra ou entre Dilma, Aécio e Marina, para ficarmos nas últimas eleições presidenciais brasileiras. Os cinco, dez ou mesmo quinze pontos percentuais que separam o líder de seu competidor mais próximo não deveriam ter peso, já que o que está em questão, na disputa, é se essa ordem de preferências se mantém ou é alterada. É o que tem procurado fazer o Jornal Nacional, da Rede Globo de Televisão, nas últimas disputas, mas seus próprios critérios de inclusão e exclusão (um determinado percentual de intenções de voto) são arbitrários e sujeitos a questionamento.

Mesmo sem contestar os limites que separam os candidatos considerados competitivos daqueles que não o são, temos problemas, já que um princípio da concorrência eleitoral democrática é a possibilidade de minorias se transformarem em maiorias. Nesse caso, todos os candidatos deveriam ter espaço igual, a fim de que suas propostas, alianças, trajetórias e comportamento fossem igualmente conhecidos e, portanto, ficassem igualmente sujeitos ao escrutínio do público. Mas então o noticiário seria poluído por oportunistas, candidatos sem votos e sem ideias, excrescências do processo democrático. A própria regra, aliás, estimularia o surgimento de candidatura deste tipo - e a cobertura política seria capturada por uma multidão de Levys Fidelixes e Josés Marias Eymaeles.

Um critério adicional poderia separar o joio do trigo, com um corte nas forças políticas "sérias", com posições que, concordemos ou não, devem legitimamente participar do debate político. É o que faz boa parte do jornalismo francês, por exemplo, que deprecia severamente o espaço concedido à extrema-direita racista, mesmo quando ela se encontra liderando as sondagens de intenção de voto - sem chegar a formar um "cordão sanitário", a imprensa francesa mostra "reticência a lhe conceder uma tribuna", segundo as palavras de Jenifer Devresse (2011, p. 4; cf. tb. Devresse, 2013). Claro que, então, a definição de quem é merecedor de acesso ao debate público e quem não o é abre espaço para incontáveis controvérsias. Caímos exatamente naquilo que a aplicação de um critério "objetivo" propunha evitar, isto é, a responsabilidade de tomar uma posição e fazer escolhas baseadas nesta posição assumida.

Todas essas alternativas, além de tudo, partem do pressuposto de que o espaço destinado a cada candidato deve ser estabelecido por regras afetas à dinâmica da disputa eleitoral. Mas é possível pensar que, pelo contrário, tais regras devem emanar das práticas do próprio jornalismo. A atribuição 
automática de espaço de acordo com critérios de relevância política pode gerar noticiários burocráticos, feitos para "cumprir tabela" - a cobertura eleitoral do Jornal Nacional, desde que ele pretensamente se converteu à imparcialidade, serve de exemplo, com suas reportagens diárias sobre eventos banais de campanha, discursos insossos e apresentação de propostas inócuas. Segunda esta visão alternativa, a cobertura da campanha eleitoral deveria, como qualquer outra cobertura jornalística, ser guiada pelos valores-notícia. Ganharia espaço no noticiário o candidato que mordesse seu cachorro.

Se essa ponderação vale para a visibilidade, vale ainda mais para a valência. Ela parece substituir a objetividade, como adesão ao mundo real, pela neutralidade como equivalência entre as partes. Se são os fatos, por seu peso intrínseco, que presidem o noticiário, não dá para evitar que ele seja mais desfavorável a uns, mais positivo para outros. Imagino o trabalho árduo do pobre repórter que tiver que ir à rua em busca das bondades de Jair Bolsonaro, a fim de equilibrar a valência negativa da cobertura dedicada a ele. $\mathrm{O}$ noticiário correto, assim, seria aquele que respeita os valores-notícia, não o que mantém equilíbrio na imagem que projeta de A ou de B.

Mas quem ainda acredita em valores-notícia? A ideia de que existe um interesse jornalístico intrínseco, detectável no código genético de cada fato e independente dos processos produtivos e dos critérios de valoração gerados socialmente no campo da imprensa, é insustentável teoricamente. Permanece, entretanto, como elemento central do autodiscurso jornalístico, aquele que pode fazer as ginásticas que quiser, mas acaba sempre, de novo, arrodeando sua paixão imorredoura, a imparcialidade (que atende também pelos nomes de objetividade ou neutralidade).

A defesa da objetividade jornalística costuma construir seu adversário como sendo algum tipo de relativismo. Seria a posição daqueles que julgam que "não há verdade, mas verdades, cujas validades são relativas ao interior das respectivas formas de vida" (Gomes, 2009, p. 42). Essa visão desloca o problema daquilo que é central: o fato de que o principal problema vinculado ao jornalismo como prática social não é a adequação ou inadequação de suas narrativas ao mundo objetivo externo (a verdade factual), mas a capacidade que ele tem de impor um conjunto de preocupações como sendo "as" preocupações relevantes, chamando a atenção para algumas temáticas e discursos, ao mesmo tempo que reduz a visibilidade de outros. 
É uma defesa que se liga à noção ingênua e conservadora de um "interesse público" que se afirma por si mesmo, desvinculado dos interesses parciais, e que é identificado, antes de ser construído. Nessa narrativa, as diferenciações sociais parecem ter caráter apenas funcional e as assimetrias no acesso à produção do discurso público são de menor importância, desde que esteja em ação uma deontologia profissional que garanta que os jornalistas assumam o ponto de vista da totalidade - os valores-notícia como especificação do interesse público, por assim dizer. Conflito de interesses é algo para os fracos.

Seja de forma rasa, seja de forma filosófica, há aí a ideia de que os fatos são os fatos e o bom jornalismo é aquele que os divulga da forma mais correta, sem vieses. Mas o entendimento de que todo discurso é socialmente situado, incluído aí o discurso do jornalismo, não implica nenhum tipo de agnosticismo epistêmico. As posições sociais geram critérios de valoração e padrões de interpretação diferenciados. Há jornalismo melhor ou pior (e certamente a manipulação deliberada ou a mentira fazem com que seja pior), mas não há jornalismo que escape de falar de uma perspectiva social específica. No entanto, boa parte da legitimidade social do discurso jornalístico advém de sua capacidade de ocultar sua própria posição de enunciação, transitando como intérprete de uma percepção universal, vinculada ao interesse geral (cf. Miguel e Biroli, 2010, pp. 68-9; ver também Biroli, 2013)5. A abordagem centrada na valência pode permitir um atalho fácil para fazer a denúncia da atuação da imprensa em momentos específicos, mas reforça esse entendimento, que impede a crítica da ideologia do jornalismo e, mais grave, compromete a possibilidade de encaminhar propostas de reforma da mídia - que devem buscar mais pluralismo, não mais "imparcialidade".

\section{Questões de mensuração, questões de compreensão}

Passo agora às questões operacionais - que são suficientes para colocar em xeque a utilidade do recurso à valência, mesmo para aqueles que, insen-

Outra abordagem que se quer um pouco mais sofisticada defende o que, seguindo Spivak, poderíamos chamar de "imparcialismo estratégico": é necessário manter o discurso da imparcialidade como forma de constranger os abusos dos controladores da mídia (por exemplo, Campos, 2015, p. 17). Há aqui ingenuidade e incompreensão do fato de que as representações do mundo social estão em conflito e a adesão ao ideal da imparcialidade é a adesão à noção de que se pode transcender e superar tal conflito, algo que trabalha objetivamente contra os interesses dos grupos desprivilegiados (que precisam fazer o esforço de apresentar sua discordância em relação ao statu quo). A afirmação do caráter necessariamente situado dos discursos implica negar tal posição. 
síveis, não se julgam convencidos pelos argumentos de fundo que esgrimi na seção anterior. A valência é uma ferramenta que promove a transformação de um conjunto de eventos complexos em um conjunto de indicadores numéricos. À parte o fetichismo quantitativo que grassa nas ciências sociais, a matematização possui inegáveis pontos positivos, sobretudo o fato de que, ao reduzir tudo a uma mesma métrica, permite a comparação entre processos diferentes entre si.

No entanto, convém lembrar que há coisas que são facilmente contáveis e há coisas que não o são. Na primeira categoria está, por exemplo, a "visibilidade no noticiário", medida em número de menções, em centímetros quadrados de página imprensa ou em segundos de telejornal. É possível tornar o quadro mais complexo, pensando em diferentes graus de visibilização conforme o espaço específico em que as menções são feitas, mas ainda assim a contagem simples representa uma aproximação bastante razoável ao fenômeno que se deseja analisar.

As coisas do segundo tipo precisam passar por processos de classificação e/ou de construção de índices antes de se transformarem em números. Cresce a possibilidade de erro humano - ou, melhor dizendo, de divergência na classificação, que sempre inclui um componente subjetivo - e surge o risco de matematização abusiva. Afinal, boa parte dos índices trabalha com variáveis de tipo dummy (aplica-se o valor 1 para presença, 0 para ausência) ou com escalas arbitrárias, em que se atribui, por exemplo, o valor 1 para "pouco frequente" e o valor 2 para "muito frequente", sem que esteja certo que "muito frequente" corresponde, de fato, ao dobro de "pouco frequente". Quando isso ocorre, o índice pode (talvez) ser útil como ferramenta descritiva, porém é impróprio para ser submetido a qualquer tipo de operação aritmética e algébrica ou tratamento estatístico. Muitos dos índices mais utilizados na ciência política desprezam tais regras, a começar pelo famoso índice de democracia atualizado anualmente pela Freedom House (Munck e Verkuilen, 2003), mas isso é porque cumprem função mais ideológica do que científica.

"Valência" é, claramente, uma dessas "coisas do segundo tipo". A atribuição do caráter positivo, negativo ou neutro carrega uma indiscutível carga de subjetividade. A indicação de como determiná-la para cada matéria inclui, de maneira central, a compreensão do que é uma referência "favorável" ou "desfavorável". Na medida em que a unidade de avaliação é a "matéria”, não cada enunciado em separado, exige também do pesquisador a capacidade de 
pesar o conteúdo “favorável” e o "desfavorável”, determinando se a resultado pende para um lado ou para o outro - ou se cai na categoria intermediária, "neutro":

Têm valência positiva matérias sobre ou com o candidato reproduzindo programa de governo; promessas; declarações do candidato ou do autor da matéria ou de terceiros (pessoas ou entidades) favoráveis (contendo avaliação de ordem moral, política ou pessoal) ao candidato; reprodução de ataques do candidato a concorrentes, resultados de pesquisas ou comentários favoráveis. Têm valência negativa matérias reproduzindo ressalvas, críticas ou ataques (contendo avaliação de ordem moral, política ou pessoal) do autor da matéria, de candidatos concorrentes ou de terceiros a algum candidato; resultados de pesquisas ou comentários desfavoráveis. São consideradas neutras as matérias sobre a agenda do candidato, matéria sobre ou citação de candidato sem avaliação moral, política ou pessoal do candidato, do autor da matéria ou de terceiros, inclusive de concorrentes. Em caso de equilíbrio entre negativo e positivo, a matéria é considerada neutra. Também levamos em conta, na avaliação da valência da matéria, que elementos editoriais como título, olhos e legenda contêm indicações sobre sua orientação e devem ser considerados no momento da análise (Aldé, Mendes e Figueiredo, 2007, pp. 158-9).

O método pressupõe que cada matéria possui uma valência em si, conforme a citação feita antes, portanto independente da decodificação promovida pela audiência. Isso representa um recuo de várias décadas na compreensão dos processos comunicativos - só para lembrar, Stuart Hall publicou "Encoding and decoding in the television discourse" em 1973. A noção de valência opera depreciando a agência tanto de emissores quanto de receptores e pressupondo uma carga semântica fixa para os enunciados. No entanto,

essa "correspondência" [entre codificação e decodificação] não é dada, mas construída. Não é "natural", mas produto de uma articulação entre dois momentos distintos. E a codificação não pode determinar ou garantir, de forma simples, quais os códigos de decodificação que serão empregados (Hall, 2003 [1980], p. 399).

De um ponto de vista mais imediato, isto significa que, não importa quão bem treinados sejam os classificadores - via de regra, estudantes de graduação movidos a bolsas de iniciação científica -, sua classificação não 
coincide necessariamente com a compreensão da matéria pelos diferentes segmentos do público. Assim, a valência confunde, de maneira sistemática, a intenção do jornal ou do jornalista, a apreciação pelos agentes políticos, o impacto na recepção e a codificação pela equipe de pesquisa, graças à ideia, insustentável do ponto de vista de qualquer teoria da comunicação minimamente sofisticada, de que o sentido das mensagens está em si.

Num passo adicional, as valências das diferentes matérias são agregadas, de maneira a indicar as frequências ou, então, estabelecer os saldos. Para isso, é necessário postular implicitamente que todos os gatos são pardos; ou, como diria Gertrude Stein, que uma valência negativa é uma valência negativa é uma valência negativa. Assim, a capa de Veja, na véspera do segundo turno das eleições presidenciais de 2014, incriminando Dilma Rousseff no escândalo da Petrobrás conta tanto quanto uma notinha, na coluna de fofocas da televisão, dizendo que o peixe que ela fez no programa de Ana Maria Braga não ficou gostoso. Num caso como no outro, ela é vinculada a atributos presumivelmente negativos. Mas não é difícil reconhecer que são afirmações não só de grandeza, mas também de natureza diferente. A equivalência entre elas compromete a validade de qualquer resultado alcançado, mesmo abstraindo os problemas metodológicos prévios. E as tentativas de solucionar esse problema só agravam o anterior, já que tentar adivinhar o peso relativo de cada matéria ampliaria ainda mais a arbitrariedade na classificação.

Em oposição a tais simplificações, qualquer compreensão do impacto do jornalismo nas disputas políticas precisa levar em consideração pelo menos três aspectos interligados: a heterogeneidade do público, a construção de sentido a longo prazo e as estratégias diferenciadas dos agentes políticos. A determinação de um "fato" como positivo ou negativo depende de percepções reproduzidas ao longo do tempo, que se ligam ao efeito cumulativo do próprio jornalismo e de outros aparelhos ideológicos. A cobertura positiva ou negativa da política econômica do governo, por exemplo, só se estabelece como positiva ou negativa a partir de um quadro de referência que sinaliza o que é certo ou errado, bom ou mau, na condução da economia.

Por outro lado, se, por exemplo, um político de direita ataca verbalmente um adversário de esquerda, a valência para o agredido seria contada como negativa. As regras citadas acima são claras: “Têm valência negativa matérias reproduzindo ressalvas, críticas ou ataques [...] de candidatos concorrentes 
[...] a algum candidato". Mas ser alvo do ataque significa ser reconhecido como polo da disputa, o que pode ser um aspecto importante da estratégia política. O que Luciana Genro não teria dado para ser atacada por Aécio Neves, nas eleições presidenciais de 2014? É importante perceber que o público do noticiário e o público do ator político se sobrepõem apenas parcialmente e que reforçar uma posição diante de uma parte dos consumidores de informação pode compensar, e muito, a sedimentação de uma imagem negativa diante de outra parte.

Os defensores da valência poderiam se defender dizendo que nada disso os interessa, já que o que importa é apenas a matéria "em si". Espero que já tenha ficado claro que este "em si" não existe. E também que, a despeito das intenções de quem os produz, os estudos de valência são consumidos como denúncias da manipulação promovida pela mídia e como indicadores de sua capacidade de influenciar as decisões políticas do público - são essas suposições implícitas que geram o interesse por eles. No entanto, suas limitações epistemológicas e metodológicas fazem com que eles não sejam capazes de alcançar adequadamente nem manipulação, nem influência.

É essa intrincada relação entre percepções construídas a longo prazo, ênfases do noticiário, estratégias políticas dos agentes e disposições diferenciadas dos diversos segmentos do público que permite avançar na compreensão de como a influência política da mídia jornalistica ocorre. Não creio que se trate de, junto com a ferramenta da valência, invalidar a ideia de que existe viés no noticiário, atribuindo tudo à dissonância cognitiva dos consumidores de informação (Gomes, 2014). O caminho é, exatamente, avançar numa compreensão mais complexa, impedindo que as debilidades do recurso à valência comprometam nossa capacidade de fazer uma crítica embasada da ação política da mídia.

\section{Conclusão}

Ainda que envolva uma dose de simplificação, é razoável pensar que todo o avanço ocorrido nos estudos sobre os efeitos sociais da mídia, das concepções hipodérmicas até hoje, foi para superar a ideia de que tais efeitos eram imediatos - no duplo sentido de instantâneos e sem mediações. As apropriações do discurso da mídia são mediadas pelos códigos e pelos quadros de referência de seus receptores; justamente por isso, seu efeito se dá em grande medida a médio prazo, na produção destes códigos e destes quadros. 
O entendimento dos efeitos políticos da cobertura do noticiário passa pela definição da agenda, que cristaliza os interesses contraditórios dos agentes em disputa; pela visibilização diferenciada dos enquadramentos sobre as questões em tela; em suma, pela construção das representações do mundo social. Agenda ou enquadramento não se traduzem numa escala bidimensional, não são facilmente transformados numa variável numérica, não garantem interpretação unívoca. São de manejo mais sutil e mais complexos exatamente porque o mundo real é mais sutil e mais complexo.

Tudo isso é jogado fora em nome de um artifício metodológico precário. Da valência é possível dizer aquilo que Pierre Bourdieu dizia dos modelos matemáticos formais, prezados pelas teorias da escolha racional e pela teoria dos jogos: sua virtude "mais indiscutível" é "revelar a contrario a complexidade do real que eles mutilam" (Bourdieu, 1980, p. 79). Para os estudos de comunicação e política, não há dúvida de que é melhor dispensar este atalho e buscar uma compreensão mais sofisticada dos seus objetos de análise.

\section{Bibliografia}

ALDÉ, Alessandra; MENDES, Gabriel \& FIGUEIREDO, Marcus (2007). “Tomando partido: imprensa e eleições presidenciais em 2006”. Política \& Sociedade, $n^{\circ} 10$, pp. 153-72.

BERABA, Marcelo (2004). "De novo, a falta de equilíbrio". Folha de S. Paulo, $12 / 9 / 2004$.

BERABA, Marcelo (2006). “O rolo compressor”. Folha de S. Paulo, 29/10/2006. BIROLI, Flávia (2013). "Limites da política e esvaziamento dos conflitos: o jornalismo como gestor de consensos". Revista Estudos Políticos, n 6, pp. 126-43.

BORBA, Felipe de Moraes (2005). Razões para a escolha eleitoral: a influência da campanha política na decisão do voto em Lula durante as eleições presidenciais de 2002. Dissertação de mestrao em Ciência Política. Rio de Janeiro: Iuperj.

BOURDIEU, Pierre (1980). Le sens pratique. Paris: Minuit.

CAMPOS, Luiz Augusto (2015). "Imprensa e esfera pública: retomando o debate Lippmann-Dewey sobre o papel público da imprensa”. Paper apresentado no $24^{\circ}$ Encontro Nacional da Compós. Brasília, 9 a 13 de junho.

DEVRESSE, Jenifer (2011). "Médias et politique: entretien avec Jenifer Devresse”. Aide Mémoire, no 55, p. 4. 
DEVRESSE, Jenifer (2013). "Problématiser les rapports entre extrême droite, médias et démocratie: les pistes de la médiation”. Paper apresentado nas Journées Doctorales de la Société Française des Sciences de l'Information et de la Communication. Paris, 30 e 31 de maio.

FOLHA de S. Paulo (2010). "Folha fez cobertura mais crítica a candidatos". Folha de S. Paulo, 3/12/2010.

GOMES, Wilson (2009). Jornalismo, fatos e interesses: ensaios de teoria do jornalismo. Florianópolis: Insular.

GOMES, Wilson (2014). “Media bias’ ou Por que o noticiário político é parcial e adversário”. Paper apresentado no IX Encontro da Associação Brasileira de Ciência Política (ABCP). Brasília, 4 a 7 de agosto.

HALL, Stuart (2003 [1980]). “Codificação/decodificação”, em Da diáspora: identidades e mediações culturais. Org. Liv Sovik. Belo Horizonte: Editora UFMG.

MANCHETÔMETRO (2014). "Metodologia”. Disponível em http://www. manchetometro.com.br/metodologia/. Acesso em 10 jun. 2015.

MARTINS, Vera Guimarães (2014). "O ônus e o bônus de Dilma (e da Folha)". Folha de S. Paulo, 5/10/2014.

MIGUEL, Luis Felipe \& BIROLI, Flávia (2010). "A produção da imparcialista: a construção do discurso universal a partir da perspectiva jornalística”. Revista Brasileira de Ciências Sociais, n 73, pp. 59-76.

MUNCK, Gerardo L. e Jay VERKUILEN (2003). "Bringing measurement back in: methodological foundations of the electoral democracy index". Paper apresentado no Annual Meeting of the American Political Science Association. Philadelphia, 28 a 31 de agosto.

MUNDIM, Pedro Santos (2014). “O viés da cobertura política da imprensa nas eleições presidenciais brasileiras de 2002, 2006 e 2010”. Paper apresentado no IX Encontro da Associação Brasileira de Ciência Política (ABCP). Brasília, 4 a 7 de agosto.

\section{Resumo}

O artigo apresenta uma crítica metodológica e política da categoria "valência", muito utilizada nos estudos brasileiros sobre comunicação e democracia. A valência só é operacionalizada à base de simplificações e mutilações da realidade que busca descrever; $\mathrm{e}$ traz implícito um ideal de imparcialidade jornalística que é questionável.

Palavras-chave: valência, imparcialidade, jornalismo. 


\section{Abstract}

The article presents a methodological and political criticism of the category "valence", widely used in Brazilian studies on communication and democracy. "Valence" operationalization is based on simplifications and mutilations of the very reality that it seeks to describe; and brings an implicit ideal of journalistic impartiality that is questionable. Keywords: valence, impartiality, news.

Recebido em 28 de abril de 2015. Aprovado em 2 de julho de 2015. 